A

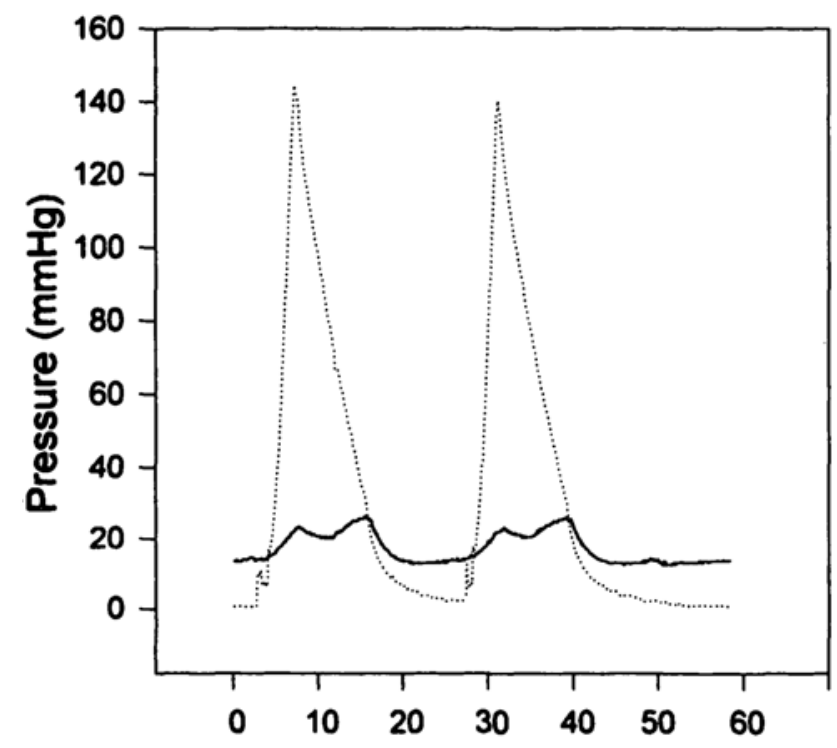

B

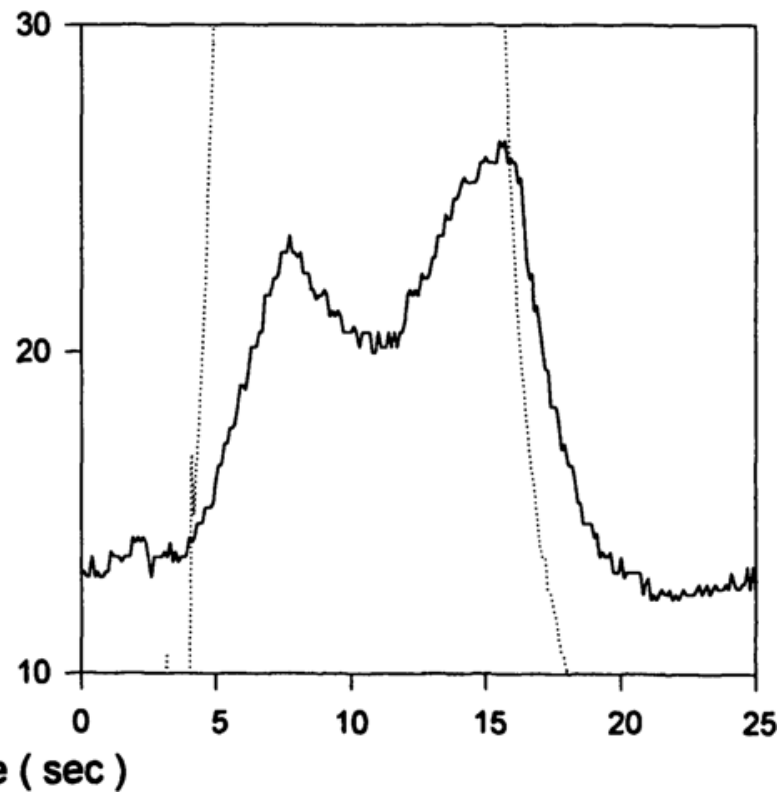

FIGURE Typical peripheral venous pressure change during NIBP monitoring. (A) Gross change in the two traces of venous pressure and cuff pressure waveform is shown. (B) Boxed area in Figure was magnified. Note that venouse pressure change is biphasic during NIBP measurement. Second peak was higher than the first peak with a notched area between.

\section{The peripheral venous pressure changes during non-invasive blood pressure measurement}

To the Editor:

Venous backflow into the infusion line and resultant occlusion can frequently occur during noninvasive blood pressure (NIBP) measurement The methods employed to counteract increase in peripheral venous pressure (PVP) include elevating the iv solution bag, routing the infusion tubing through the $\mathrm{BP}$ cuff so that it is sandwiched between the Velcro layers, ${ }^{1,2}$ or placing a check valve within the iv tubing, etc. However, these methods are used empirically without any experimental background on the change in the PVP. In this study we tried to obtain the pattern and range of PVP change during NIBP measurement before and during enflurane anesthesia.

PVP waveforms during NIBP measurement were recorded from six subjects., and PVPs were measured and compared before induction and at $30 \mathrm{~min}$ after induction of enflurane anesthesia (n7-19).

As a result, PVP change was biphasic in shape during NIBP monitoring (Figure). Second peak, which occurs during deflation period, was always higher than the first peak. Range of peak PVP was $12-130 \mathrm{mmHg}$ ( $57 \pm 3 \mathrm{mmHg}$, mean \pm S.E.) and PVP change was augmented during enflurane anesthesia $(32.9 \pm 2.9$ $\mathrm{mmHg}$ before anesthesia vs $70.4 \pm 5.4 \mathrm{mmHg}$ after anesthesia; $P<0.05$ ).

In conclusion, we found that peripheral venous pressure during NIBP measurement peaks at deflation phase, and the range of the PVP change is augmented by enflurane anesthesia. These patterns and the range of PVP change should be kept in mind when we apply methods to counteract venous regurgitation during NIBP monitoring.

\section{J.Y. Sim MD \\ Y. Choi MD \\ M.J. Yoon MD \\ D.M. Lee MD \\ J.W. Leem PhD \\ Seoul, Korea}

\section{References}

1 Wait CM. Blood pressure measurements and intravenous infusions (Letter). Anaesthesia 1992; 47: 1012. 
2 Maekawa $N$, Mikawa $K$, Nishina $\Upsilon$, Kiyonari $\Upsilon$, Obara $H$. A simple device for preventing retrograde flow of blood into intravenous lines caused by blood pressure measurements (Letter). Anesth Analg 1996; 83: 665. 